\title{
Risky Sexual Behavior of Modern Teenager's Current Challenges
}

\author{
Darina Koskina \\ Taras Shevchenko National University of Kyiv, Kiev, Ukraine \\ E-mail address: darinakoskina@gmail.com
}

\begin{abstract}
This article deals with some ways of conceptualizing and prevention of adolescent risky behavior. Specific ways for preventing and managing risky sexual behavior are discussed. Anonymous interviews in Ukrainian schools have demonstrated, that sexual activity (including sexual intercourse) is common among adolescents. The risk is that it may cause diseases in reproductive system and unwanted pregnancy. Modern psychologists are widely attracted to this area because of the revolutionary societal changes during last decades.
\end{abstract}

Keywords: sexual behavior; modern teenagers; risky sexual behavior; sex education

\section{INTRODUCTION}

Adolescents routinely engage in behaviors that put their health at risk. Clinicians, psychologists and sexologists are faced with 3 challenges: (1) how to understand this behavior, (2) how to identify risky sexual behavior in the adolescent patient, and (3) what to do about it (Hall et al., 2004).

Studying issues of sexual behavior among adolescents for a long time was under the ban in post-Soviet countries. However, current situation in adolescent's health level requires scientists in different domains to research teenage sexual behavior. As it is wide-known, health problems with reproductive system may occur through the invasion into immature reproductive sphere. Teenager's age accompanied by intense sexual maturation and concomitant psychological realities - awakening of sexual interest, gaining experience of sexual behavior.

Teenager's psychosexual development inevitably faces them with many items, such as responsibility in sexual relationships. Definitely, the onset of sexual activity is a new way to acquire emotionally rich experience. It leads to formation of fundamentally different skills in relationship with the opposite sex. Teens are trying to order new norms and values and embed them into their self-concept. Thus we consider, that both psychologists and parents should care about preventing the risky sexual behaviors in adolescents.

\section{RISKY ADOLESCENT SEXUAL BEHAVIOR}

The notion of risky sexual behavior includes such acts as unprotected intercourse, early sexual activity, having multiple sex partners and others. Risky sexual behavior may lead to the 
prevalence of sexually transmitted diseases, HIV/AIDS, abortions, prostitution, pornography, pedophilia etc. Moreover, numerous studies have linked a greater prevalence of high-risk sexual behaviors to teens with mental health disorders (Chavis, 2010).

Within the framework of anonymous interview in Ukrainian schools (15-17-year old pupils), we have discovered that the majority of adolescents are sexually active $(60 \%)$, yet many do not take appropriate precautions to prevent pregnancy or the spread of sexually transmitted infections.

The survey has shown, that modern Ukrainian teenagers use Internet as a source of knowledge about sexual life $(U=577 ; p=0,012)$. They also prefer discuss this topic with their friends, who also can have low level of sexological knowledge.

Also we have figured out that stereotypes enormously influence adolescent's sexual behavior. Thus, surveyed teens view sexual contact without love as a normal thing $(p=0.003)$. Both sexes (but especially boys) think that it is typical for women to use sex as a manipulation $(\mathrm{p}=0.049)$. Pupils also disapprove sexual relationship of people of different races. They treat gay relationship as more unpleasant phenomenon than a lesbian relationship $(p=0.039)$.

Historically, we know that language and vocabulary have some effect on the human psyche. That is why we have tried to draw attention to this aspect in adolescent sexual behavior. Then it was found that adolescents actively $(p=0.007)$ use obscene language to title genitalia and sexual intercourse. Such an approach may depreciate and devalue the touching nature of the intercourse.

The risk of unplanned pregnancy increases with frequency of unprotected sexual intercourse. Estimates have suggested that approximately 35-40\% of adolescent American women (aged 15 to 19 years) become pregnant before age 20 years (Zelazo et al., 1997; Hamilton et al., 2002), and most of these pregnancies are unintended. Unfortunately, there is no data about unintended pregnancies among Ukrainian teenagers.

The study revealed that boys find frequent change of partners as more immoral for women than for men. This type of view indicates not only the presence of stereotypes in their views, but also a non-egalitarian way of thinking.

Young men, unlike women, believe that rape is more provoked by girls $(\mathrm{U}=607 ; \mathrm{p}=$ 0,003). This result may indicate the resistance attitudes on the traditional role and trend of shifting the responsibility on the other. This result confirms and spread the idea that seductive behavior can cause women's rape. This point of view mostly refers to young men (3.23) than woman $(2,48)(U=615 ; p=0,002)$.

Risky sexual behavior can take several forms, ranging from a large number of sexual partners to sexual intercourse under the influence of substances such as alcohol or cocaine. The problem is that it may be difficult for the psychologists to discern that these activities are occurring, especially since the adolescent is unlikely to volunteer this information. Assessment of risky sexual behavior is somewhat challenging. Measurement of behavior usually relies on verbal reports, which can suffer from a number of biases, both intentional and unintentional.

\section{PREVENTING THE RISKY SEXUAL BEHAVIOR}

Specific recommendations for assessing and managing risky sexual behavior are still being discussed. Thought they may include maintaining an empathic stance toward the adolescent, supporting the autonomy of the adolescent, identifying and owning one's own values, familiarizing oneself with available resources, and referring to mental health 
practitioners when appropriate (Hall et al., 2004). Progress in preventing or reducing risky sexual behavior can be assessed by comparing survey results over time. Data on risky sexual behaviors can be collected monthly or quarterly, depending on the length of the program.

The prevention of many health-risk behaviors among high school students may be done by obligatory sex education. Functional sex education can reduce the real and potential threats in sexual behavior. Since the sexuality is not fixed, but it matures and develops, sex education may contribute to prevent risky adolescent sexual behavior.

In the majority of Europe countries, sex education is the part of school curricula. It normally covers all subjects concerning the process of growing up, bodily changes during puberty, emotions involved, the biological process of reproduction, sexual activity, partnership, homosexuality, unwanted pregnancies and the complications of abortion, the dangers of sexual violence, child abuse, and sex-transmitted diseases.

In the United States sex education is taught in two main forms: comprehensive and abstinence-only. Comprehensive sex education covers abstinence as a choice option, but also informs adolescents about the availability of contraception and techniques to avoid contraction of sexually transmitted diseases. Abstinence-only sex education emphasizes abstinence from sexual activity prior to marriage and rejects methods such as contraception. The difference between the two approaches, and their impact on the behavior of adolescents, remains a controversial subject in the United States and all over the world.

Sex education represents the instruction on issues relating to human sexuality. It may include general human sexual anatomy, sexual reproduction, sexual activity, reproductive health, emotional relations, reproductive rights and responsibilities, sexual abstinence, and birth control. Sex education can be given by parents, psychologists, formal school programs or public health campaigns.

Sexual behavior is a sensitive topic that many adolescents find difficult to discuss with adults. Psychologists can facilitate such discussions by adopting a nonjudgmental attitude toward the adolescent. Sex education, provided by both clinicians and psychologists can break down the barriers, supply teenagers with required information in this field.

\section{CONCLUSION}

Teenage sexual behavior is largely determined by the sexual culture of society, which is a necessary component of sexual education. Risky sexual behavior defines modern teenagers at the transitional stage of development of Ukrainian society, which is characterized by a departure from taboos in sexuality.

Contradictions in psychosexual development of modern teenagers negatively influence their self-concept, self-esteem, the total maturing. We assume that lots of problems in this domain can be solved by obligatory sex education, which, for instance, will inform teenagers about the aftermath of early sexual activity.

\section{References}

[1] Centers for Disease Control and Prevention (2010). Youth Risk Behavior SurveillanceUnited Sates, 2009. MMWR, 59 (No.SS-5), 1-142.

[2] Chavis S. (2010). Risky Sexual Behaviors and Anxiety, Depression, PTSD. Psych Central. Retrieved on May 24, 2014. 
[3] Hall P., Holmqvist M., Sherry S. (2004). Risky Adolescent Sexual Behavior: A Psychological Perspective for Primary Care. Topics in Advanced Practice. Nursing eJournal, 4(1).

[4] Hamilton B. E., Martin J. A., Sutton P. D. (2003). Births: preliminary data for 2002. National Vital Statistics Reports, 51(11).

[5] Hovorun T., Sharhan O. (1990). Parents about sex education of children. Kyiv: The Soviet School.

[6] Hopkins J. R. (1997). Sexual behavior in adolescence. Journal of Social Issues 33(2), 67-85.

[7] Hyde J. (1994). Understanding Human Sexuality. New York: McGraw-Hill.

[8] Zelazo P. D., Carter A., Reznick S., Frye D. (1997). Early development of executive function: a problem solving framework. Review of General Psychology, 1(2), 198-226. 